\title{
LA CREACIÓN DE UN NUEVO ORDEN PÚBLICO EUROPEO EN MATERIA DE PRIVACIDAD COMO PRESUPUESTO PARA SU GARANTÍA INTEGRAL
}

\author{
THE DEVELOPMENT OF A NEW EUROPEAN PUBLIC \\ POLICY ON PRIVACY AS A PRECONDITION FOR ITS \\ COMPREHENSIVE GUARANTEE
}

\author{
Marina Sancho LóPez \\ Profesora Ayudante Doctora \\ Universitat de València
}

Recibido: 20.06.2021 / Aceptado: 12.07.2021

DOI: https://doi.org/10.20318/cdt.2021.6316

\begin{abstract}
Resumen: La normativa reciente en materia de protección de datos así como los pronunciamientos del Tribunal de Justicia de la Unión Europea en la cuestión y del Tribunal Europeo de Derechos Humanos sobre el derecho a la vida privada, refuerzan la idea de la existencia de un orden público europeo distinto del orden público interno e internacional de cada Estado miembro. En este sentido, se ha venido conformando una estrategia comunitaria y un orden público europeo en torno a la concepción de la vida íntima y familiar y, en particular, al propio concepto de privacidad, cuyo alcance y significación difiere de la conceptualización que, sobre estos elementos, se ha venido realizando por la doctrina y jurisprudencia doméstica de los Estados miembros.
\end{abstract}

Palabras clave: privacidad, protección de datos, intimidad, reglamento europeo.

Abstract: Recent legislation on data protection, as well as the case law of the European Court of Justice on the issue and the case law of the European Court of Human Rights on the right to privacy, reinforce the idea of the existence an European public policy separate from the internal and international public policy of each Member State. In this sense, a Community strategy and a new European public policy has been shaping around the concept of intimate and family life and, in particular, the concept of privacy itself. The scope and meaning of privacy differs from the conceptualisation of these elements in the legal doctrine and the case law of the Member States.

Keywords: privacy, data protection, intimacy, European regulation.

Sumario: I. Consideraciones preliminares; II. Divergencias conceptuales entre lo íntimo y lo privado; III. Un orden público europeo en materia de privacidad; 1. La protección de datos como motor de cambio; 2. Disonancias con los órdenes internos e internacionales. Especial mención al caso del Reino Unido; IV. Conclusiones. 


\section{Consideraciones preliminares}

1. La realidad tecnológico-digital presente, gracias a la democratización de Internet y a la expansión de las tecnologías inteligentes del Big data han provocado cambios sustanciales en diversos espectros, desde la economía hasta las formas de interacción y relación social ${ }^{1}$. En este contexto, la recolección, almacenamiento y tratamiento en masa de los datos personales de la ciudadanía es una constante cuya trascendencia se ve acrecentada por la interacción constante de Internet donde todo es público -incluso lo privado- y además es permanente en el tiempo, lo que indudablemente tiene una repercusión en la merma de ciertos derechos fundamentales.

2. Este cambio de paradigma, debido al aumento exponencial del flujo de información personal y la interconexión de las diferentes bases de datos que los almacenan, ha comprometido la vida privada tal y como la conocíamos -ahora más expuesta que nunca-, comportando un aumento e incluso una alteración de la naturaleza y la intensidad de los riesgos de sufrir un daño real. En palabras de PÉREz LuÑo ${ }^{2}$ nos encontramos ante un "asalto tecnológico de los derechos y libertades", donde resulta difícilmente negable la injerencia de la informática de control individual y colectivo que comprometen gravemente valores como la identidad, dignidad e igualdad, e incluso la propia seguridad jurídica.

3. Así, ciertas conductas que antes podrían considerarse remotas o de mínimo riesgo, se han convertido en lesiones potenciales, teniendo en cuenta además, el efecto multiplicador propiciado por las nuevas tecnologías del Big data. Estos riesgos para la vida privada, que en muchos casos terminan en lesión, han venido exigiendo un proceso profundo de reflexión por parte del Derecho para adaptar sus proposiciones al nuevo estado de cosas donde conceptos jurídicos que antes no presentaban mayores discusiones, como la vida privada, han cambiado en su significado y significación.

4. En definitiva, la privacidad personal está más expuesta que nunca y las probabilidades de causarle lesiones han aumentado en la coyuntura digital actual, por ello, con el objeto de adecuar sus presupuestos estructurales a la protección de la vida privada y a la autodeterminación informativa, desde las instancias europeas se ha tratado de construir mecanismos jurídicos que sean capaces de garantizar la privacidad de la ciudadanía en su acepción más contemporánea, conformando un nuevo orden público europeo.

5. $\mathrm{Y}$ es que una sociedad avanzada exige repensar los términos y medios de tutela de la esfera privada de sus ciudadanos, como consecuencia lógica del desarrollo garantista de los derechos de la personalidad frente a los desafíos que se presentan en cada momento para los bienes jurídicos protegidos. Por ello, como se verá a continuación, el ámbito de protección de lo privado se ha venido extendiendo conforme han ido aumentando las posibilidades de injerencia, debido a la connivencia del Big data e Internet.

6. En consonancia con esto, la normativa comunitaria en materia de protección de datos, los pronunciamientos del Tribunal de Justicia de la Unión Europea en la cuestión y la jurisprudencia del Tribunal Europeo de Derechos Humanos definiendo lo privado, refuerzan la existencia de un orden público europeo distinto del orden público interno e internacional de cada Estado miembro en torno a la concepción de la vida íntima y familiar y, en particular, sobre el alcance y significación de la privacidad, difiriendo de la doctrina y jurisprudencia doméstica, como se examinará más adelante.

\footnotetext{
${ }^{1}$ Ciertamente nos encontramos ante un cambio de paradigma pues los cambios introducidos por la trascendencia de los datos personales en todos los campos son de tal magnitud que su trascendencia que abarca la propia configuración del tejido social. Como señalan MAYER-SCHÖNBERGER y CUKIER, "la era de los datos masivos pone en cuestión la forma en que vivimos e interactuamos con el mundo [...] Esto da al traste con las prácticas establecidas durante siglos y choca con nuestra comprensión más elemental acerca de cómo tomar decisiones y aprehender la realidad”. V. MAYER-SCHÖNBERGER Y K.CUKIER, Big data. La revolución de los datos masivos, Turner, Madrid, 2015, p. 18.

${ }^{2}$ A. E. PÉRez LuÑo, Los derechos humanos en la sociedad tecnológica, Universitas, Madrid, 2012, p. 23.
} 


\section{Divergencias conceptuales entre lo íntimo y lo privado}

7. Frecuentemente se confunden los términos "intimidad" y "privacidad", los cuales se emplean a menudo, de manera errónea, como sinónimos tanto en el ámbito jurídico como en el lenguaje coloquial. Sin embargo, estos términos, aunque es indiscutible que se encuentran intrínsecamente relacionados, divergen notablemente en cuanto a su alcance y contenido por lo que deben usarse con propiedad.

8. La razón de dicha confusión se debe, fundamentalmente, a motivos históricos y filológicos en tanto que la protección de la vida privada tiene su origen en la construcción anglosajona privacy ${ }^{3}$ que ha sido incorporada en nuestra tradición jurídica indistintamente como "lo privado" o "intimidad" aunque, sin embargo, ambos términos divergen en su significado etimológico ${ }^{4}$ y jurídico al representar, respectivamente, un espacio de protección para el individuo mayor o más estricto respecto de su esfera personal ${ }^{5}$.

9. Así, mientras que el derecho a la intimidad se relaciona con el poder que cada individuo tiene para controlar la injerencia externa en su esfera más íntima, el derecho a la privacidad permite controlar el acceso, el alcance y la difusión de los demás a ese dominio íntimo. Igualmente, mientras que la intimidad es necesaria para salvaguardar la autonomía personal y el libre desarrollo de la personalidad, la privacidad abarca una dimensión mayor en el contexto de las relaciones interpersonales, proporcionando un espacio libre para llevar a cabo una multiplicidad de actos entre los que se incluye el intercambio de información personal. De este modo, intimidad y privacidad son realidades distintas aunque relacionadas y tienen un objetivo común: la ausencia de difusión -resguardarse de la publicidad no deseada-, reservando al individuo una parcela libre de injerencia ${ }^{6}$.

10. A diferencia de la intimidad, el ámbito de protección de la privacidad es flexible y está sujeta a cambios, por lo que depende de cada persona, del contexto, de las pautas de comportamiento de un lugar, de las costumbres o de las necesidades sociales. Por ello, mientras que sobre el concepto de intimidad existe cierto consenso en la doctrina ${ }^{7}$, no hay criterios uniformes para determinar aquello que constituye la "vida privada", pues dicha concepción varía sustancialmente según las circunstancias en las que se someta a examen e incluso en función de las expectativas personales.

\footnotetext{
${ }^{3}$ Comúnmente se ha acordado en situar el origen de la protección del derecho a la vida privada en los planteamientos llevados a cabo en el siglo XIX por WARREN y BRANDEIS, que defendieron la existencia en el common law de un derecho a no ser molestado "the right to be let alone". S. D. Warren/ L.D. BrandeIs, "The Right to Privacy", Harvard Law Review, vol. IV, n" 5, 1890.

${ }^{4}$ Como señala DESANTES GUANTER, mientras que la palabra "privacidad" deriva del latín privatus, la "intimidad" procede del latino intimus que es una variación de intumus, forma superlativa del verbo intus cuyo significado es "dentro", por lo que "intimidad" alude a aquello que está lo más dentro posible del ser humano, el ámbito más reservado de su personalidad. J.M. Desantes Guanter, "Intimidad e información, derechos excluyentes" en Nuestro tiempo, no 213, Pamplona, 1972.

${ }^{5}$ En este sentido se elabora la Teoría de los círculos concéntricos en la doctrina alemana, cuyo origen se sitúa en las disertaciones de Hubmann aunque posteriormente fue reelaborada por el Tribunal Constitucional Alemán y ha sido una teoría acogida en nuestra tradición jurídica, entre otros, por Desantes GuAnTER y SoRIA. Según dicha teoría, debe diferenciarse entre tres niveles de confidencialidad o secretismo: primeramente, la esfera más íntima del individuo (Intimsphäre) impermeable a cualquier intromisión, a continuación la esfera privada (Privatsphäre) más permeable, en la que se incluyen aspectos personales y familiares menos íntimos y asemejada al right to privacy del common law y, finalmente, en un tercer nivel se delimita la esfera más pública pero aún protegida (Privatsphäre) en la que se incluyen aspectos relativos al honor y a la propia imagen. H. Hubmann, Das Persönlichkeitsrecht, Böhlau, Colonia, 1967; J. M. Desantes Guanter y Soria, Los límites de la información. La información en la jurisprudencia del Tribunal Constitucional: las 100 primeras sentencias, APM, Madrid, 1991.

${ }^{6}$ E. Garzón Valdés, “Lo íntimo, lo privado y lo público", en Claves de la razón práctica, no 137, Madrid, 2003, p.15.

${ }^{7}$ Las definiciones que proporcionan la mayoría de los autores no difieren sustancialmente entre ellas, aunque ciertamente pueden apreciarse matices. Como muestra, AlBALADEJo entiende la intimidad personal como "el poder concedido a la persona sobre el conjunto de actividades que forman un círculo íntimo, personal y familiar, poder que le permite excluir a los extraños de entrometerse en él y de darle una publicidad que no desee el interesado", M. Albaladejo García, Derecho Civil I. Introducción y Parte General, Edisofer, Madrid, 2009, p. 460; Dítz PicAzo y A. Gullón lo definen como "la esfera secreta de la propia persona que debe ser protegida contra las intromisiones e indagaciones ajenas”, L. Dízz PicAzo y A. Gullón. Sistema de Derecho Civil, Tecnos, Vol. 1, Madrid, 1992, p. 340; Para LóPez Guerra se trata del "reducto más privado de la vida del individuo, esto es, aquellos extremos más personales de su vida y su entorno familiar”. L. López GuERRA, Derecho Constitucional, Tirant lo Blanch, València, 2007, p. 231.
} 
11. En consecuencia, la noción de privacidad es más idónea para describir la realidad presente, en la que el Big data en concurrencia con la revolución informática y tecnológica, ocasionan riesgos y lesiones para ciertos ámbitos personales de los individuos que, sin penetrar necesariamente en su estricta intimidad, calan en su ámbito más privado, suscitando igualmente molestias y perjuicios.

12. Podría decirse, de acuerdo con el orden público europeo en esta cuestión, que la privacidad es aquella esfera personal integrada por informaciones y comportamientos que, pese a no ser íntimos, el individuo desea que sólo sean conocidos por él o por determinadas personas con las que voluntariamente quiera compartirlos, sustrayendo su conocimiento a núcleos más amplios de la sociedad ${ }^{8}$. Y es que la privacidad varía en función de la naturaleza de las relaciones interpersonales que se desenvuelvan en un determinado contexto, constituyéndose por reglas de convivencia que tienden a preservar la intimidad personal y se erigen como barreras a la invasión de lo público ${ }^{9}$.

13. La intimidad no se opone a lo privado pues ambas radican en la defensa de la autonomía y la necesidad de un dominio reservado para la plena realización de los individuos, diferenciándose por su dimensión e intensidad de protección. Así, el derecho a la privacidad permite controlar el acceso, el alcance y la difusión de los demás al dominio íntimo. Mientras que la intimidad es necesaria para salvaguardar la autonomía personal y el libre desarrollo de la personalidad, la privacidad abarca una dimensión mayor en el contexto de las relaciones interpersonales, proporcionando un espacio libre para llevar a cabo una multiplicidad de actos entre los que se incluye el intercambio de información personal ${ }^{10}$.

14. Se trata, en definitiva, de una evolución natural, más acorde con el contexto económicodigital actual y con una mayor garantía para la vida privada de las personas. La protección jurídica de lo privado, hasta hace poco quedaba circunscrita al ámbito íntimo, como se deriva del artículo 18 de la Constitución española, de tal modo que, con el avance de las nuevas tecnologías y la evolución de las pautas de comportamiento social, ello había supuesto, a nivel práctico, una disminución considerable del alcance de la garantía de dicho precepto, limitando su protección a aquellos aspectos más íntimos de los sujetos y dejando sin tutela determinadas conductas que, si bien constituyen una intromisión en la privacidad personal, no vulneran el estricto ámbito de la intimidad.

15. Con la creación y desarrollo del derecho a la protección de datos personales se han intentado paliar estas carencias garantistas ${ }^{11}$ que, fundamentalmente han venido de mano de la legislación europea, tal y como se expondrá a continuación. Principalmente, mediante la promulgación del Reglamento (UE) $n^{\circ}$ 2016/679 del Parlamento y del Consejo, de 27 de abril de 2016, relativo a la protección de las

\footnotetext{
${ }^{8}$ Álvarez-Cienfuegos SuÁrez también distingue, junto con la intimidad, "una esfera más amplia y quizá de protección menos enérgica que recibe el nombre de privacidad, siguiendo el anglicismo de la privacy. La cual viene referida a datos o informaciones no íntimos, pero que el individuo desea que sólo sean conocidos por determinadas personas, queriendo sustraer su conocimiento a núcleos más amplios de la sociedad”. J. M. Álvarez-Cienfuegos SuÁrez, La defensa de la intimidad de los ciudadanos y la tecnología informática, Aranzadi, Pamplona, 1999, p. 71.

${ }^{9} \mathrm{Vid}$. H. BÉJAR, El ámbito intimo. Privacidad, individualismo y modernidad, Alianza, Madrid, 1989.

10 "The content of privacy cannot be captured if we focus exclusively on either information, access, or intimate decisions because privacy involves all three areas [...] privacy's content covers intimate information, access, and decisions. The problem with understanding privacy as intimacy, however, is that not all private information or decisions we make are intimate"'. J. C. InNES, Privacy, Intimacy and Isolation, Oxford University Press, New York, 1992, p. 56.

${ }^{11}$ De hecho, la primera ley española de protección de datos, la Ley Orgánica 5/1992, de 29 de octubre, de regulación del tratamiento automatizado de los datos de carácter personal -LORTAD- (BOE 31 octubre 1992), diferenciaba expresamente entre el concepto de intimidad y privacidad, precisamente para extender la protección de dicha ley cualquiera que fuese el grado de lesión, sin distinguir entre el ámbito privado y el ámbito íntimo, cosa que no se ha vuelto a producir en las siguientes normas que la han venido sucediendo. De acuerdo con la exposición de motivos: "Nótese que se habla de la privacidad y no de la intimidad: Aquélla es más amplia que ésta, pues en tanto la intimidad protege la esfera en que se desarrollan las facetas más singularmente reservadas de la vida de la persona -el domicilio donde realiza su vida cotidiana, las comunicaciones en las que expresa sus sentimientos, por ejemplo-, la privacidad constituye un conjunto, más amplio, más global, de facetas de su personalidad que, aisladamente consideradas, pueden carecer de significación intrínseca pero que, coherentemente enlazadas entre sí, arrojan como precipitado un retrato de la personalidad del individuo que éste tiene derecho a mantener reservado".
} 
personas físicas en lo que respecta al tratamiento de datos personales y a la libre circulación de estos datos y por el que se deroga la Directiva 95/46/CE (Reglamento general de protección de datos), DOUE de 27 de abril 2016 (de acuerdo con sus siglas en inglés, GDPR en adelante), directamente aplicable a los Estados miembros, cuyos principios y articulados han cambiado las reglas del juego en materia de protección de datos.

16. No obstante, hay que reconocer que antes de la promulgación del GDPR, la jurisprudencia española ya interpretaba extensivamente el concepto de vida privada, por ejemplo, en la SAN 29 diciembre 2014 (5129/2014), dictada a raíz del procedimiento que elevó al Tribunal de Justicia de la Unión Europea (TJUE en lo que sigue) las cuestiones prejudiciales que dieron lugar a la Sentencia del Caso Google ${ }^{12}$ y que resulta relevante en la medida que incorpora por primera vez la doctrina del TJUE en el caso Google en nuestra jurisdicción ${ }^{13}$.

17. También el propio Tribunal Constitucional, al reconocer el carácter autónomo y fundamental del derecho a la protección de datos, en su STC 30 noviembre 2000 (292/2000), invoca el artículo 18.4 de la Constitución española (CE) para reconocer en él la existencia de un nuevo derecho y, para ello, extiende el ámbito de la intimidad del artículo 18.1 CE hacia la protección de la privacidad, dónde se insertaría el derecho a la protección de los datos personales, admitiendo que, en ocasiones, ambas figuras pueden llegar a solaparse ${ }^{14}$. Asimismo lo reitera la STC 4 junio 2018 (58/2018), al reconocer que la vida privada de la persona y de su reputación posee en la actualidad un ámbito propio y una dimensión positiva que excede del perímetro del derecho fundamental a la intimidad del artículo 18.1 CE y que se traduce en un derecho de control sobre los datos relativos a la propia persona, encontrando abrigo en el artículo $18.4 \mathrm{CE}^{15}$.

18. De este modo, se reconoce el valor constitucional de lo privado en un sentido comunitario, mucho más amplio que la concepción individualista de la intimidad, evolucionando hacia un ideal integrador. Se toma consciencia pues, de que la privacidad no es un valor absoluto sino que tiene un carácter mutable que varía en función del contexto social y que, como señala de LóPEZ JACOISTE ${ }^{16}$ es muy sensible a las conceptualizaciones del momento así como voluble respecto de las amenazas que en cada situación pueden peligrar la integridad de los derechos personales.

19. Con todo ello se han intentado paliar las indeseables consecuencias que generaba la impunidad de ciertas intromisiones en la privacidad de las personas que, sin embargo, no cumplían todos los requisitos que para la protección de la intimidad se exigen. De este modo, con el reconocimiento de una esfera de protección mayor, más acorde con la realidad digital y que puede asimilarse con la privacidad, a través de la protección de datos, se procura una tutela jurídica a las nuevas facetas de la vida privada.

${ }^{12}$ STJCE 13 mayo 2014, Google Spain, S.L., Google Inc. y Agencia Española de Protección de Datos, Mario Costeja González, as. 131/12, ECLI:EU:C:2014:317.

${ }^{13}$ Después de dicha resolución, la Audiencia Nacional hizo públicas las primeras dieciocho sentencias relativas al derecho al olvido, que resolvían los recursos contencioso-administrativos interpuestos por Google Spain contra las resoluciones estimatorias de la Agencia Española de Protección de Datos (AEPD) y cuyo fallo, en base a la doctrina de la STJUE del caso Google, fue estimatorio en catorce de dichos casos, entre ellos, la SAN 19 junio 2017 (2562/2017), la SAN 13 julio 2017 (3257/2017) o la SAN 18 julio 2017 (3029/2017).

${ }^{14}$ En este sentido afirma el TC: "Este derecho fundamental a la protección de datos, a diferencia del derecho a la intimidad del art. 18.1 CE, con quien comparte el objetivo de ofrecer una eficaz protección constitucional de la vida privada personal y familiar, atribuye a su titular un haz de facultades que consiste en su mayor parte en el poder jurídico de imponer a terceros la realización u omisión de determinados comportamientos cuya concreta regulación debe establecer la Ley, aquella que conforme al art. 18.4 CE debe limitar el uso de la informática, bien desarrollando el derecho fundamental a la protección de datos (art. 81.1 CE), bien regulando su ejercicio (art. 53.1 CE). La peculiaridad de este derecho fundamental a la protección de datos respecto de aquel derecho fundamental tan afín como es el de la intimidad radica, pues, en su distinta función, lo que apareja, por consiguiente, que también su objeto y contenido difieran" (FJ 5).

${ }^{15} \mathrm{FJ}^{\circ}$.

${ }^{16}$ J. J. LÓPEZ JACOISTE, “Una aproximación tópica a los derechos de la personalidad”, en Anuario de Derecho Civil, Vol. 39 , $\mathrm{n}^{\circ} 14,1986$, pp. 1059-1120. 


\section{Un orden público europeo en materia de privacidad}

\section{La protección de datos como motor de cambio}

20. El impacto del GDPR ha sido muy significativo a distintos niveles, en términos generales, el Reglamento evidencia la irreversible europeización de la estrategia pública de protección de los derechos fundamentales frente al poder y el avance de la tecnología y la informática, que ya fue iniciada por la derogada Directiva 95/46/CE del Parlamento Europeo y del Consejo, de 24 de octubre de 1995, relativa a la protección de las personas físicas en lo que respecta al tratamiento de datos personales y a la libre circulación de estos datos, DOUE de 23 noviembre 1995. Asimismo, el artículo 8 de la Carta de Derechos Fundamentales de la Unión Europea ${ }^{17}$ consiguió elevar a rango constitucional europeo el derecho fundamental autónomo a la protección de datos y que, además, la jurisprudencia europea -principalmente el TJUE- ha reafirmado con sus numerosos pronunciamientos, argumentando la prevalencia de los derechos fundamentales sobre la tecnología ${ }^{18}$. Todo ello, más específicamente y en relación con lo que venimos tratando, ha supuesto una expansión del concepto de privacidad y de su perímetro de protección, más allá del estricto ámbito concedido a la intimidad, tradicionalmente protegida a nivel doméstico.

21. El GDPR se dicta teniendo en consideración las amenazas que para los derechos fundamentales provocan las nuevas tecnologías, así como el uso masivo de datos derivado de éstas. En este sentido, afirma: "el tratamiento de datos personales debe estar concebido para servir a la humanidad. El derecho a la protección de los datos personales no es un derecho absoluto sino que debe considerarse en relación con su función en la sociedad y mantener el equilibrio con otros derechos fundamentales, con arreglo al principio de proporcionalidad" $19 \mathrm{y}$, en consecuencia, apuesta notablemente por dotar a los ciudadanos de auténticos poderes de control sobre su información personal.

22. Esta legislación parte de la idea de que la información personal debe estar sometida al criterio del propio interesado, suponiendo un cambio radical en materia de protección de datos, por una parte, porque dota al titular de los datos de todo tipo de derechos para facilitar la gestión de su información personal en base a sus preferencias (como el derecho de supresión o de portabilidad de los datos) y, de otra parte, porque somete la actuación de empresas privadas y administraciones públicas a los intereses generales de la ciudadanía, obligándoles a adoptar políticas activas de protección de datos y cambiando las reglas de juego existentes.

23. A través de la protección de datos, se amplía el ámbito de protección de la esfera privada de las personas para evitar las injerencias que habitualmente vienen acompañadas del uso y abuso de las nuevas tecnologías, que han sido capaces de romper las fronteras físicas que protegían la privacidad de las personas y que, además, tienen un efecto multiplicador para las lesiones de los distintos derechos de la personalidad.

24. La conformación de un orden público europeo en este sentido, implica una clara apuesta por un modelo garantista de los derechos y libertades de las personas en tanto que configura la protección jurídica de los datos personales - privacidad, en última instancia-como condición material para asegurar la libertad individual de los sujetos, permitiendo el libre desarrollo de su personalidad. Se trata así de adecuar los presupuestos jurídicos a la realidad social para lograr una efectividad de los derechos y libertades fundamentales más allá de la evolución de la técnica y las circunstancias del medio concomitante, ejecutando las funciones del Derecho de adaptarse a la realidad social imperante.

\footnotetext{
${ }^{17}$ Carta de los derechos fundamentales de la Unión Europea, de 7 de diciembre de 2000, DOUE de 7 de junio 2016.

${ }^{18}$ C. Ruiz Miguel, "El derecho a la protección de datos personales en la Carta de Derechos Fundamentales de la Unión Europea: análisis crítico", en Revista de Derecho Comunitario Europeo, n 14, pp. 7 ss.

${ }^{19}$ Considerando cuarto del Reglamento (UE) no 2016/679 del Parlamento y del Consejo, de 27 de abril de 2016, relativo a la protección de las personas físicas en lo que respecta al tratamiento de datos personales y a la libre circulación de estos datos y por el que se deroga la Directiva 95/46/CE (Reglamento general de protección de datos), DOUE de 27 de abril 2016.
} 
25. Aunque de forma más bien tímida, sería ésta una postura deudora del garantismo elaborado por FERRAJOLI, en relación con su defensa de la subordinación de la legitimidad del ordenamiento jurídico al aseguramiento de las condiciones materiales efectivas de disfrute de los derechos fundamentales ${ }^{20}$. Los derechos fundamentales, en tanto que carecen de un valor ontológico, emergen como respuesta a las dinámicas de transformación social y varían con éstas, garantizando en última instancia el respeto a la dignidad de la persona para desarrollarse de forma plena de acuerdo con el principio general de libertad. Así pues, la garantía unitaria de los derechos y las libertades fundamentales depende de la tutela jurídica del ámbito de la vida privada de los sujetos -definido como privacidad-pues, como ya defendió ConsTANT siglos atrás, cuando diferenciaba entre la libertad de los antiguos -basada en la participación activa y constante en el ejercicio del poder colectivo- y la libertad de los modernos -basada en el disfrute apacible de la independencia privada-, la privacidad es un presupuesto indispensable para la protección de la gran mayoría de los derechos individuales ${ }^{21}$.

26. En este proceso, la jurisprudencia europea del Tribunal de Luxemburgo ha sido vital a la hora de configurar la estrategia europea de protección de datos, destaca la ya mencionada sentencia STJUE en el caso Google ${ }^{22}$-pronunciamiento que se erigió en el leading case en materia de derecho al olvido- que estableció lo que más tarde consagró el Reglamento europeo de protección de datos personales y es el principio de extraterritorialidad de la legislación en materia de protección de datos, haciendo extensible la responsabilidad sobre el borrado de datos personales a los gestores de los buscadores de Internet, incluso cuando no estén domiciliados en España, pero realicen su actividad por medio de un establecimiento permanente sito en ella ${ }^{23}$. Con ello, el Tribunal extiende la aplicación de la legislación comunitaria más allá de los actores europeos, incluyendo también a todos aquellos que desempeñen su actividad en su territorio.

27. Asimismo, con su resolución, el TJUE afirmó rotundamente que el tratamiento de datos personales por los buscadores en Internet puede afectar significativamente a los derechos fundamentales de las personas, en relación con el respeto a la vida familiar y a la protección de los datos personales, cuando la búsqueda se lleva a cabo a partir del nombre de una persona física, pues ello permite al internauta hacerse una configuración apriorística de una persona en base a la lista de resultados ofrecidos ${ }^{24}$. Por ello, debe entenderse esta sentencia como una declaración del principio general de prevalencia del derecho a la protección de datos de carácter personal, sobre cualquier aspecto o limitación tecnológica, pues toda implementación de herramientas o dispositivos tecnológicos habrá de permitir siempre el ejercicio de este derecho fundamental en sus distintas manifestaciones ${ }^{25}$.

28. El Tribunal de Luxemburgo, hace hincapié en el alto nivel de protección otorgado al derecho de protección de datos por la Directiva 95/46/CE del Parlamento Europeo y del Consejo, de 24 de octubre de 1995, relativa a la protección de las personas físicas en lo que respecta al tratamiento de datos personales y a la libre circulación de estos datos, DOUE de 23 noviembre 1995; el artículo 8 del Convenio Europeo de Derechos Humanos de 1950 (CEDH en adelante) ${ }^{26}$ y los principios generales de

\footnotetext{
${ }^{20}$ Para FERRAJOLI "el garantismo opera como doctrina jurídica de legitimación y sobre todo de deslegitimación interna". El autor italiano denomina democracia sustancial al sistema dotado de garantías efectivas, tanto liberales como sociales, donde se manifiestan los derechos fundamentales de los ciudadanos frente a los poderes del Estado, constituyendo así una doctrina de legitimación. L. Ferrajoli, Derecho y razón. Teoría del garantismo penal, Trotta, Madrid, 2009, p. 864.

${ }^{21}$ B. Constant, Cours de Politique Constitutionelle, Didier, París, 1836, 1836.

${ }^{22}$ STJCE 13 mayo 2014, Google Spain, S.L., Google Inc. y Agencia Española de Protección de Datos, Mario Costeja González, as. 131/12, ECLI:EU:C:2014:317.

${ }^{23}$ Resolvió así la STJUE que la filial para venta publicitaria de Google en España (Google Spain) era un establecimiento que llevaba a cabo tratamiento de datos, pues su actividad estaba indisociablemente ligada a la de su filial en Estados Unidos Google Inc. (puntos 55 y 60), rechazando la argumentación del motor de búsqueda en dicho sentido.

${ }^{24}$ Para. $38-40$ y 80.

${ }^{25}$ J. Plaza Penadés, "Doctrina del Tribunal de Justicia de la Unión Europea sobre protección de datos y derecho al olvido" en Revista Aranzadi de Derecho y Nuevas Tecnologías, nº 35, 2014, p. 18.

${ }^{26}$ Convenio para la Protección de los Derechos Humanos y de las Libertades Fundamentales, de 4 de noviembre de 1950 , BOE de 10 octubre 1979.
} 
Derecho comunitario, al cual otorga un alcance constitucional derivado del contenido de los artículos 7 y 8 de la Carta de los Derechos Fundamentales de la Unión Europeo ${ }^{27}$ (CDFUE en lo que sigue) de 2010 que reconocen, respectivamente, el derecho a la vida privada y a la protección de datos personales. La relevancia jurisprudencial de esta resolución debe entenderse desde una óptica garantista y la necesidad de hacer evolucionar el Derecho al mismo compás que la sociedad. En un momento en que la desconexión tecnológica parece ya imposible, deben darse respuestas jurídicas a los problemas que ocasionan las nuevas herramientas tecnológicas respecto de los derechos y las libertades consolidados.

29. En términos generales, la jurisprudencia del TJUE constituye una referencia precisa sobre los enormes riesgos potenciales para la privacidad del individuo que derivan del uso de servicios y dispositivos tecnológicos en los que se almacena abundante información personal sin que el principio de territorialidad estatal pueda satisfacer las garantías necesarias para evitar la lesión en la vida privada. Por ello, la fuerza expansiva extraterritorial de los pronunciamientos del TJUE ha sido un factor clave a la hora de proteger los derechos de los ciudadanos europeos más allá de las fronteras de la Unión.

30. De hecho, el TJUE se ha convertido en un auténtico juez garante de la privacidad ante la evolución tecnológica global como se ha podido observar en muchas de sus resoluciones como el caso Digital Rights en relación con la Directiva 2006/24/CE del Parlamento Europeo y del Consejo, de 15 de marzo de 2006, sobre la conservación de datos generados o tratados en relación con la prestación de servicios de comunicaciones electrónicas de acceso público o de redes públicas de comunicaciones y por la que se modifica la Directiva 2002/58/CE ${ }^{28}$, DOUE de 14 abril 2016; el caso Facebook respecto del Safe Harbour ${ }^{29} \mathrm{o}$, como se ha mencionado anteriormente, el caso Google ${ }^{30}$, para el derecho al olvido ${ }^{31}$. El reconocimiento por el artículo 8 del CEDH de la protección de la intimidad y la vida privada propicia el marco de referencia normativo adecuado para el posterior desarrollo jurisprudencial por el case law de la esfera de privacidad del sujeto.

31. En este sentido, puede observarse el reconocimiento del habeas data como un poder activo de control sobre la privacidad, tal y como dispone la STEDH 3 abril 2017, Copland v. United Kingdom, as. 62617/00, ECLI:EU:ECHR:2008:1204JUD003056204 ${ }^{32}$, o la interrelación construida por el Tribunal de Estrasburgo entre vida privada y protección de datos, en el leading case STEDH S. 4 diciembre 2008, and Marper v. United Kingdom, as. 30562/04 and 30566/04 [GC] $]^{33}$.

32. Así pues, se constata la conformación de un orden público europeo en materia de protección de datos, con la intención de proteger el sentido y finalidad comunitaria en estas cuestiones. Por este motivo, el GDPR trata de aportar un régimen unitario y global en materia de protección de datos, con una voluntad claramente integradora cuya finalidad es reducir el margen de actuación de los órdenes públicos internos e internacionales en la materia, como puede observarse en el cambio de estrategia normativa, pasando de una Directiva -la Directiva 95/46/CE - a un Reglamento -el GDPR 2016/67934-,

${ }^{27}$ Carta de los derechos fundamentales de la Unión Europea, de 7 de diciembre de 2000, DOUE de 7 de junio 2016.

${ }^{28}$ STJCE 8 abril 2014, Digital Rights Ireland Ltd, as. 293/12, ECLI:EU:C:2014:238.

${ }^{29}$ STJCE 6 octubre 2015, Maximillian Schrems, as. 362/14, ECLI:EU:C:2015:650.

${ }^{30}$ STJCE 13 mayo 2014, Google Spain, S.L., Google Inc. y Agencia Española de Protección de Datos, Mario Costeja González, as. 131/12, ECLI:EU:C:2014:317.

${ }^{31}$ M. Arenas Ramiro, "El derecho a la protección de datos personales en la jurisprudencia del TJCE”, en Revista Aranzadi de Derecho y Nuevas Tecnologías, Vol. 4, 2006, p. 97.

32 "este Tribunal considera que la obtención y almacenamiento de datos personales obtenidos sin el conocimiento previo del sujeto, a partir de su teléfono móvil o su cuenta de correo electrónico, supone una interferencia en el disfrute de su esfera personal de privacidad" (para. 44). De este modo, se lleva a cabo una interpretación del art. 8 CEDH mediante la cual se entiende incluido dentro del derecho a la vida privada el propio control de la información personal obtenida por terceros, permitiendo con ello la limitación de las posibles interferencias en la esfera de privacidad del sujeto dentro del contexto Big data.

33 "el mero almacenamiento de datos personales, relacionados con la vida privada de un sujeto equivale a una inferencia en el sentido del art. 8, que garantiza el derecho al respeto de la vida privada y familiar", para. 67.

${ }^{34}$ El propio GDPR reconoce que, aunque los objetivos de la Directiva 95/46/CE siguen siendo válidos, la aplicación dispar 
precisamente para evitar las disparidades existentes entre los Estados miembros (en especial, en materia sancionadora y acerca de la legitimación pasiva) y seguir una estrategia común con una clara intención europeizadora en la cuestión ${ }^{35}$.

33. Este nuevo orden público europeo en materia de privacidad se plantea en algunos casos, como se verá a continuación, con cierta distancia respecto de los órdenes internos e internacionales de los Estados miembros en materia de privacidad, que han tenido que adaptar sus modelos al estándar europeo. En el caso español, por ejemplo, ello ha obligado a incrementar las fronteras de protección constitucional de lo privado, como puede observarse en la SAN 25 julio (3260/2017), donde la Audiencia Nacional señala que el derecho a la protección de datos personales, de conformidad con el GDPR, tiene un objeto mucho más amplio que el derecho a la intimidad, al extender su garantía a la esfera de los derechos de la persona que pertenecen al ámbito de la vida privada, más allá del núcleo constitucional reservado para la intimidad, incluyendo así a cualquier tipo de dato personal ya sea éste íntimo o no.

\section{Disonancias con los órdenes internos e internacionales. Especial mención al caso del Reino Unido}

34. Sin embargo, este nuevo orden público europeo ha colisionado con las conceptualizaciones propias de los Estados miembros, provocando conflictos respecto de su armonización a efectos materiales con las normativas nacionales en materia de protección de datos. Así ocurrió, por ejemplo, tal y como se incidirá a continuación, con el Reino Unido y su noción del right to privacy, condicionada por la tradición jurídica de common law y la articulación de la Human Rights Act 1998, de 9 de noviembre de 1998, así como la máxima rule of law en dicho sistema jurídico.

35. En nuestro sistema jurídico, ya desde un primer momento, la publicación del GDPR suscitó dudas sustanciales en cuanto a la articulación de los derechos de transparencia, información, acceso, rectificación, supresión, limitación del tratamiento, portabilidad de datos y oposición, todos ellos recogidos en el reglamento, con los tradicionales derechos ARCO (acceso, rectificación, cancelación y oposición) de la doctrina española. Esta discrepancia entre órdenes públicos en la materia, también se ha puesto de relieve como evidencia la reciente STS 27 noviembre 2020 (1624/2020), acerca del ejercicio del derecho al olvido y en donde queda reflejada la disparidad de criterios en torno a la conceptualización de la identidad de toda persona y al significado del nombre y los apellidos de cada individuo.

36. En este caso concreto, la cuestión se plantea porque el demandante pretende obtener la desindexación de los enlaces que ofrece un determinado buscador cuando se introduce su nombre y su apellido en el mismo, lo que considera una injerencia en el derecho al respeto de su vida privada. Sin embargo, al interesado se le deniega el ejercicio de su derecho de supresión alegando, por una parte, que la legislación española reguladora del Registro Civil, que es la encargada de determinar cuáles son los elementos identificativos de los ciudadanos, considera que una persona se identifica inequívocamente por su nombre y sus dos apellidos ${ }^{36}$. Por otra parte, según dispone la sentencia de instancia, se infiere de la doctrina del Tribunal de Justicia de la Unión Europea en el Caso Google, que sólo procede estimar

\footnotetext{
y fragmentada de la misma por parte de los distintos Estados miembros, ha generado inseguridad jurídica y no ha permitido hacer frente a los riesgos existentes para la protección de datos. Literalmente, en su considerando 9: "Esta diferencia en los niveles de protección se debe a la existencia de divergencias en la ejecución y aplicación de la Directiva 95/46/CE".

${ }^{35}$ Ello también puede observarse con la decisión del GDPR de extender el principio de extraterritorialidad más allá del territorio de la Unión (artículo 3) o la previsión de adoptar medidas de privacidad desde el diseño y por defecto para la protección de datos (artículo 25), tratando de crear una política común europea en la materia y de extender los estándares europeos más allá de las fronteras de la UE.

${ }^{36}$ Según el articulo 53 de la Ley de 8 de julio de 1957, sobre el Registro Civil (BOE de 6 diciembre) "Las personas son designadas por su nombre y apellidos".
} 
una reclamación de desindexación cuando la búsqueda se realice a partir de los dos apellidos de la persona afectada y no exclusivamente a partir de uno, por muy singular que éste sea.

Resolviendo el recurso de casación, finalmente el Tribunal Supremo estima que la legislación europea y la jurisprudencia del TJUE no pueden verse limitadas por las operativas de los Estados miembros y su regulación interna en materia registral pues ello supondría contravenir "el espíritu y finalidad tuitiva de la normativa de la Unión Europea" $\left(\mathrm{FJ}^{\circ}\right.$ ) y, en consonancia, ampara el derecho de supresión del interesado.

37. Precisamente, en relación con esta cuestión, el legislador nacional ha dado un paso atrás en el espíritu garantista de la norma comunitaria en materia de protección de datos dado que, a través del artículo 93 de la Ley Orgánica 2/2018, de 5 de diciembre, de Protección de Datos Personales y garantía de los derechos digitales (BOE 10 junio 1957) -LOPDGDD-, limita de facto el derecho al olvido, restringiendo su actuación exclusivamente respecto de las búsquedas realizadas por nombres y apellidos no afectando ello a las fuentes originales y, por tanto, a las búsquedas que se realicen por cualquier otra palabra o término. Esta interpretación era la originaria del TJUE pero debe considerarse ya superada pues meramente obedece al carácter embrionario del derecho al olvido ${ }^{37} \mathrm{y}, \sin$ embargo, en la práctica, esta postura supone una indefensión para el interesado por la excesiva carga procesal que acarrea tratar de borrar de la lista de resultados sus datos personales en función de todas las variantes disponibles para acceder a ellos y que, en definitiva, supone que dicha información no desaparecerá nunca de Internet.

38. Así pues, en materia de protección de la vida privada y familiar, más allá de los contornos propios de cada Estado miembro (por ejemplo, legislando acerca de la edad de los menores para prestar el consentimiento o respecto del alcance del derecho al olvido sobre las webmaster fuente) parece clara la conformación de un orden público europeo que, además, se ha revelado como la mejor estrategia, desde una óptica garantista, para velar por el respeto a los derechos y libertades fundamentales en materia de protección de datos.

39. El caso del Reino Unido ha sido especialmente peculiar en esta materia por diversos motivos. Primeramente porque, si bien se ha convenido en situar la creación del derecho a la privacidad en el artículo que en 1890 escribieron WARREN y BRANDEIS titulado "The right to privacy" 38 , la evolución de este nuevo derecho se desarrolló de forma distinta en la vertiente americana y anglosajona del common law. Históricamente, el common law anglosajón no reconocía ningún derecho a la privacidad ${ }^{39}$ ni tampoco contemplaba un derecho de responsabilidad civil, sin embargo, sí que ofrecía remedios parciales, principalmente, a través de las figuras de la breach of confidence (revelación de secretos), el trespass (allanamiento), la nuisance (perjuicio, molestias) o la defamation and malicious falsehood (difamación).

40. Así, pese a que en el ordenamiento jurídico británico no es posible encontrar definición alguna del derecho a la privacidad, debido al reconocimiento sectorial y específico de algunas de sus facetas, en la práctica anglosajona la vida privada engloba una multiplicidad de garantías: el derecho a no ser molestado, de evitar la publicidad de ciertos aspectos personales, a la protección del copyright, a estar libre de injerencias por parte de las autoridades públicas, a la propiedad privada, a la confidencialidad, a un tratamiento de datos personales justo y adecuado a la Ley, a no ser fotografiado en estancias privadas, al secreto empresarial, etc.

\footnotetext{
${ }^{37}$ Sobre esta cuestión, puede destacarse la posición de living instrument conferida al Convenio, en la STEDH 25 abril 1978, Tyrer v. United Kingdom, as. 5856/72, ECLI:CE:ECHR:1978:0425JUD000585672. Considerar el CEDH como un instrumento vivo supone reforzar, no únicamente la vigencia del texto, sino la propia protección de los derechos humanos contenidos en su articulado. Efectivamente, cuando el Tribunal de Estrasburgo desarrolla una interpretación atendiendo al objeto y propósito del Convenio, lo hace de acuerdo con la realidad cambiante propia de las sociedades democráticas de los Estados parte.

${ }^{38}$ S. D. Warren/ L.D. BrandeIs, “The Right to Privacy”, Harvard Law Review, vol. IV, no 5, 1890.

39 "[In United Kingdom] the common law has not developed an overall remedy for the invasion of privacy", Court of House Lords 16 octubre 2003, Wainwright v. Home Office, [2003] UKHL 53, 3 WLR 1137.
} 
41. No fue hasta el Convenio $\mathrm{n}^{\circ} 108$ del Consejo de Europa, de 28 de enero de 1981, para la protección de las personas con respecto al tratamiento automatizado de datos de carácter personal, primer instrumento internacional jurídicamente vinculante adoptado en el ámbito de la protección de datos, cuando el Reino Unido estableció los pilares de lo que sería el derecho a la protección de datos moderno, a través de la Data Protection Act 1984, de 12 de julio de 1984, convirtiéndose en una de las primeras leyes en materia substancial de protección de datos en todo el mundo. Por ello, tradicionalmente, en el Reino Unido se ha vinculado la tutela de la privacidad con la protección de datos ya que, a través de esta legislación específica -que sí que goza de protección específica y se configura como una obligación legal clara- se ha concretado un derecho más amplio como la privacidad, aunando tradicionalmente ambos conceptos hasta el punto de servirse como sinónimos en determinadas ocasiones ${ }^{40}$.

42. La aprobación de la Human Rights Act 1998, de 9 de noviembre de 1998 (HRA en adelante), supuso un punto de inflexión en la materia en tanto que, a partir de entonces, se incorporaron a la legislación británica los derechos y libertades garantizados por el Convenio Europeo de Derechos Humanos de 1950 (CEDH en lo que sigue), resultando directamente aplicables, así como la jurisprudencia del Tribunal Europeo de Derechos Humanos (TEDH) interpretando dichos preceptos, dejando éste de ser un órgano de segunda instancia ${ }^{41}$. La HRA, paliando la ausencia de una Bill of Rights en el ordenamiento constitucional británico, convirtió el CEDH en Derecho vinculante para los poderes públicos británicos, proclamando los derechos recogidos en la nueva norma como una suerte de declaración de derechos fundamentales para su ciudadanía ${ }^{42}$.

43. La entrada en vigor de la HRA supuso el reconocimiento del derecho a la privacidad gracias a su artículo 8 -que reproduce literalmente el contenido del Artículo 8 del $\mathrm{CEDH}^{43}$-, derecho que no había tenido soporte legal específico en la legislación británica pero que, a partir de entonces, se instituyó como un bien jurídico autónomo a proteger, aproximándose a la doctrina más continenta ${ }^{44}$. Desde un punto de vista formal, el artículo 8 comprende cuatro elementos: vida privada, vida familiar, hogar y correspondencia pero, sin embargo, aunque la garantía de este precepto es heterogénea -protegiendo desde la identidad sexual hasta la protección de datos personales-, redunda en la protección de la esfera personal de un individuo, confiriéndole un espacio seguro y libre de injerencias salvo en algunas circunstancias y por motivos tasados ${ }^{45}$.

44. Además de convertir en vinculante el contenido del CEDH, la HRA impone a todos los poderes públicos la obligatoriedad de actuar, en el ejercicio de sus funciones, de forma compatible con los derechos del CEDH, lo que incluye también a la judicatura ${ }^{46}$. A partir de entonces, los órganos ju-

${ }^{40}$ K. A. Bamberguer/D. K. Mulligan, Privacy on the Ground. Driving Corporate Behavior in the United States and Europe, Massachusetts Institute of Technology Press, Cambridge, 2015, p. 150.

41 "Bring Rights Home" fue el eslogan utilizado por el partido laborista, entonces en el gobierno, para escenificar la importancia de la aprobación de la HRA. De hecho, en la presentación del proyecto de la HRA, se incidió en que dicho texto normativo no suponía la creación de nuevos derechos para los británicos sino que se dotaba de eficacia directa a los mismos con el objetivo de que los tribunales dispusieran de mecanismos suficientes para su efectiva protección. Sin embargo, eran muchos los derechos del CEDH que no se recogían en el common law británico, entre ellos, el derecho a la vida privada y familiar.

${ }^{42}$ Sobre la Human Rights Act y la vinculación del CEDH al sistema jurídico británico, desde la perspectiva del sistema de justicia penal, recomendamos la publicación de J. Correcher Mira, Principio de legalidad penal: ley formal vs. law in action, Tirant lo Blanch, Valencia, 2018, pp. 179-207.

${ }^{43} 1$. "Toda persona tiene derecho al respeto de su vida privada y familiar, de su domicilio y de su correspondencia. 2. No podrá haber injerencia de la autoridad pública en el ejercicio de este derecho sino en tanto en cuanto esta injerencia esté prevista por la ley y constituya una medida que, en una sociedad democrática, sea necesaria para la seguridad nacional, la seguridad pública, el bienestar económico del país, la defensa del orden y la prevención de las infracciones penales, la protección de la salud o de la moral, o la protección de los derechos y las libertades de los demás".

${ }^{44} \mathrm{La}$ transcendencia de la HRA en este contexto se puso de relevancia por Lord Hoffman en el famoso caso Campbell: "lo que ha hecho la Human Rights Act es identificar la vida privada con algo que merece la pena proteger, como un aspecto fundamental de la autonomía personal y la dignidad humana", Campbell v. Mirror Group Newspapers Ldt [2004] UKHL 22.

${ }^{45}$ Connors v. United Kingdom [2005] 40 EHRR 9.

${ }^{46}$ La jurisprudencia anglosajona ya había puesto de relieve la desprotección de los ciudadanos en su esfera privada y la 
risdiccionales del Reino Unido tienen la obligación de interpretar la legislación de conformidad con el Convenio así como acatar en todo lo posible la jurisprudencia emanada del TEDH.

45. De hecho, la jurisprudencia del TEDH y su forma de interpretar el artículo 8 del Convenio ha sido esencial en la formación y aplicación jurídica del derecho a la privacidad por los tribunales británicos, concediendo virtualidad al artículo 8 de la HRA así como dotándolo de contenido ${ }^{47}$. Se han venido integrando elementos diversos que incluyen, desde aspectos eminentemente íntimos (como la integridad física y psicológica ${ }^{48}$, la identificación del género, el nombre, la orientación o vida sexual $)^{49}$, hasta elementos con un componente más social, al entender que dicho precepto protege también el derecho a la identidad y el desarrollo personal y el derecho a establecer relaciones con otros seres humanos y el mundo exterior ${ }^{50}$.

46. Este último aspecto supuso un punto de inflexión al extender la protección de la privacidad fuera de la esfera estrictamente personal, en base a la existencia de una zona de interacción interpersonal que, incluso en un contexto público, puede subsumirse dentro del ámbito de la vida privada ${ }^{51}$. De este modo, la protección de la vida privada rebasa la estricta esfera íntima de una persona ${ }^{52}$ y va mucho más allá de una prerrogativa ciudadana al constituir una obligación positiva del Estado que tiene que disponer los instrumentos necesarios para impedir que los individuos sufran cualquier interferencia en su ámbito más privado ya sea por parte de otros individuos, administraciones públicas ${ }^{53}$ o empresas

injusta impunidad de ciertas conductas lesivas debido a la omisión de un remedio legal a tal efecto: "It is well-known that in English law there is no right to privacy, and accordingly there is no right of action for breach of a person's privacy. The facts of the present case are a graphic illustration of the desirability of Parliament considering whether and in what circumstances statutory provision can be made to protect the privacy of individuals". The Supreme Court of Judicature Court of Appeal (civil división) 16 marzo 1991, Kaye v. Robertson, [1991] FSR 62.

${ }^{47}$ Como se ha visto, el contenido literal del artículo 8 del CEDH emplea términos muy genéricos como "vida privada" o "injerencia" sin añadir nada más a dichas definiciones. La brevedad de la referencia no es casual, obedece a una estrategia global con finalidad garantista y voluntad de permanencia, para facilitar su aplicación al máximo de supuestos inimaginables. Así, se evita limitar el ámbito de protección mediante la introducción de notas características o requisitos que puedan inutilizar la aplicación del derecho a futuras circunstancias. Otra cuestión distinta es si, las legislaciones domésticas no incorporan más detalladamente y conforme a sus estándares nacionales estos derechos y libertades que, igualmente serán realizables y exigibles ante los Tribunales, pudiendo ello indicar una falta deliberada de su garantía pero no su inexistencia o ineficacia. Sin embargo, esta generalidad, ha hecho necesario que la jurisprudencia desarrolle y perfile el contenido de dicho precepto en numerosas ocasiones. Así por ejemplo, los tribunales han determinado que una condena penal no supone por sí misma una interferencia con la "vida privada", pues el artículo 8 no protege al individuo frente a una pérdida de reputación que tiene lugar por una mala praxis del sujeto o cuando se trate de un acto u omisión que haya tenido lugar respecto de una persona con un cargo público en el ejercicio de sus deberes. STEDH 3 abril 2012 (GC), Gillberg v. Sweden, as. 41723/06, [2012].

${ }^{48}$ La jurisprudencia ha matizado que en ella se integra también la salud mental, como un elemento esencial de la vida privada, asociado con el aspecto de la identidad moral. Entre otras, STEDH 28 enero 2003, Peck v. United Kingdom, as. 44647/98, [2003] ECHR 44, (2003) 36 EHRR 41, [2003] 36 EHRR 719.

${ }^{49}$ Es tal la amplitud del precepto que ha sido invocado en supuestos tan extremos como la determinación de una calidad de vida suficiente de acuerdo con la dignidad humana y el desarrollo de la propia personalidad. Así se determinó en la STEDH 29 abril 2002, Pretty v. United Kingdom, as. 2346/02 [2002] ECHR 423, en la que el TEDH aceptó la aplicabilidad del artículo 8 en un caso de asistencia al suicidio.

${ }^{50}$ Court of Appeal 11 marzo 2022, A v. B plc, [2002] 3 WLR 542.

${ }^{51}$ Por ello, las expectativas razonables de privacidad de una persona, aunque son un factor significativo, no es determinante pues hay ocasiones en que las personas se involucran en actividades a sabiendas de que son o pueden ser divulgadas públicamente.

${ }^{52}$ Estas distintas facetas del artículo 8 pueden observarse a través de la distinta jurisprudencia al respecto, entre otras, la STEDH 16 diciembre 1992, Niemietz v. Germany, as. 13710/88 [1992] 16 EHRR 97, donde el TEDH advirtió de que el concepto "vida privada" no podía quedar limitado al círculo personal en el que un individuo elige vivir su vida, sino que debe ir más allá, abarcando un círculo mayor en el que una persona se relaciona con otras; la STEDH 12 enero 2010, Gillan v. UK, as. 4158/05 [2010], donde la Corte de Estrasburgo afirmó que este derecho incluía la búsqueda de los orígenes personales, en relación con el desarrollo de la personalidad individual; la STEDH 24 febrero 1998, Botta v. Italy, as. $21439 / 93$ [1998] 26 EHRR 241, donde este precepto se enfocaba hacia el derecho a la autodeterminación personal; o la STEDH 20 marzo 2007, Tysiac v. Poland as. 5410/03, [2007] 22 BHRC 155 en el que se ponía de relieve el alcance a la integridad física o moral.

${ }^{53}$ High Court of Justice Queen's Bench Division 14 febrero 2002, Theakston v. MGN Ltd, [2002] EMLR 398. 
privadas, reconociendo el efecto horizontal de dicho precepto $^{54}$ en la posibilidad de ejercitarse entre particulares ${ }^{55}$.

47. Así pues, el derecho a la privacidad comporta obligaciones negativas pero también positivas para las autoridades públicas ${ }^{56}$ que deben abstenerse de producir injerencias al tiempo que adoptan políticas públicas de protección ${ }^{57}$. Este aspecto dual le ha dado al precepto gran parte de su notoriedad, tanto en el derecho europeo como en el doméstico pues, desde las primeras decisiones en virtud del artículo 8 que reconocían obligaciones positivas cuando se derivaban consecuencias graves para los derechos fundamentales, el aspecto positivo de éste ha representado una parte muy significativa de la jurisprudencia del TEDH ${ }^{58}$.

48. Sin embargo, la interpretación del TEDH también ha evidenciado la discrepancia entre órdenes públicos pues, por ejemplo, en algunos casos ha extendido el paraguas legal del artículo 8 dotando de protección a personas jurídicas ${ }^{59}$, lo que ha sido un aspecto muy controvertido debido a que el Derecho inglés, igual que ocurre con la difamación y la reputación, no reconoce esta protección jurídica más allá de las personas físicas ${ }^{60}$.

49. El valor otorgado por dicha normativa a la jurisprudencia del TEDH, junto con el valor tradicional que se le brinda a jueces y tribunales británicos en el derecho anglosajón -mediante normas estatutarias y los instrumentos clásicos del common law como la breach of confidence o el trespass, que han servido para instrumentalizar las garantías introducidas por la HRA-, han conferido una gran flexibilidad al concepto y garantía de la privacidad.

50. Todo esto teniendo en cuenta que conceptualizar la privacidad ha resultado particularmente difícil para la doctrina británica, fundamentalmente porque en la tradición jurídica del common law no ha existido históricamente un ámbito consistente para la protección de la privacidad personal, sino que ésta a menudo viene identificada como una cortapisa a la esfera de libertad personal, conceptos que a menudo entran en colisión y que en la doctrina británica se presentan inherentemente ligados. Por ello, la aprobación de la Human Rights Act 1998 constituye un elemento fundamental para la protección de la privacidad en la legislación británica, ya que permitió dotar a los tribunales británicos de herramientas efectivas para otorgar su reconocimiento directo y explícito pues, antes de la aprobación de la HRA, la legislación inglesa no era capaz de dar respuestas satisfactorias a problemas sociales cotidianos ${ }^{61}$.

${ }^{54}$ Court Chancery Division (Ch) 7 noviembre 2003, Michael Douglas \& Catherine Zeta-Jones v. Hello! Ldt, [2003] EWHC 2629. De este modo, el derecho a la privacidad no sólo es accionable verticalmente por una persona individual frente al Estado, sino que también tiene efectos horizontales indirectos, pudiendo ejercitarse entre particulares. De hecho, el artículo 8 del $\mathrm{CEDH}$ es, mayoritariamente invocado en disputas entre particulares o entre particulares y corporaciones y, en menor medida, frente al Estado.

${ }^{55}$ Esta extensión del artículo 8 del CEDH hacia las disputas entre particulares ha tenido gran apoyo de la jurisprudencia, siendo el caso $X v$. The Netherlands, de 26 de marzo de 1985, ECHR 4 [1985] 8 EHRR 235, el más significativo.

${ }^{56}$ Estas obligaciones positivas pueden ser de la más diversa índole pudiendo consistir, por ejemplo, en medidas legislativas encaminadas a garantizar el consentimiento informado (STEDH 23 marzo 2010, MAK and RK v. United Kingdom, as. 45901/05 y 40146/06 [2010] ECHR 363) o a la prevención de la violencia doméstica (STEDH 14 octubre 2010, A v. Croatia, as. $55164 / 08)$.

${ }^{57}$ Así, en la STEDH 26 marzo 1985, $X$ and $Y$ v. the Netherlands, as. 8978/80 ECHR 4 [1985] 8 EHRR 235, el TEDH afirmó: "[Article 8] does not merely compel the state to abstain from interference: in addition to this primarily negative undertaking, there may be positive obligations inherent in an effective respect for private and family live [...] these obligations may involve the adoption of measures designed to secure respect for private life even in the sphere of relations between individuals themselves".

${ }^{58}$ J. Wadham/H. Mountfield/E. Prochaska, Blackstone's guide to The Human Rights Act, 1998, Oxford University Press, Oxford, 2015, p. 232.

${ }^{59}$ STEDH 16 enero 2008, Wieser and Bicos Beteiligungen v. Austria, as. 74336/01 [2008] 46 ECHR 54.

${ }^{60}$ Así, por ejemplo, en la sentencia 7 abril 1993, Derbyshire County Council v. Times Newspapers, [1993] AC 534, la Cámara de los Lores determinó que una autoridad pública no puede instar una demanda por ataques a su reputación.

${ }^{61}$ Como puso de relevancia el caso Kaye v. Robertson en en 1991 en el que no se pudo prohibir la publicación de unas fotografías tomadas ilegítimamente en el interior de un hospital porque, de acuerdo con la ley británica, no había ninguna previsión legal al respecto pese que era notorio por el tribunal, que se estaba cometiendo una injusticia, tal como dispuso en el fallo 
51. Queda patente como la evolución del modelo de protección de la privacidad en el Reino Unido reviste ciertas peculiaridades, empezando por la dicotomía de su sistema legal, que ha llegado a aunar dos corrientes aparentemente contrapuestas, esto es, de un lado su tradición jurídica del common law, íntimamente ligado al precedente judicial y, de otro, un positivismo jurídico creciente a raíz de la integración europea, adoptando el principio de soberanía nacional mediante el cual se legitima al Parlamento para legislar en cualquier ámbito del Derecho. Este particular fenómeno se une al hecho de que el Reino Unido no cuenta con una constitución escrita, sino con lo que ha sido llamado "unwritten constitution", que otorga fuerza vinculante al common law, a las disposiciones normativas de origen parlamentario así como a los tratados internacionales, y es a través de estos instrumentos y siguiendo el criterio orientador de la rule of $l a w^{62}$, que se provee a la ciudadanía de derechos y libertades exigibles.

52. Recientemente, se ha detectado una disminución notable del modelo británico de protección de la privacidad, a consecuencia de la legislación dictada en los últimos quince años, cuyo exponente máximo lo encontramos en la Data Retention and Investigatory Powers Act 2014 (DRIPA), de 17 de julio de 2014, declarada contraria al Derecho de la $\mathrm{UE}^{63}$. Por otra parte, con la consolidación del Brexit y para evitar acabar con el flujo de datos entre el Reino Unido - que ha pasado a considerarse un tercer estado- y la UE, el Gobierno británico ha aprobado la Data Protection Act 2018, de 25 de mayo de 2018, contemplando en su legislación doméstica el marco normativo europeo forjado con el GDPR. Sin embargo, se plantean numerosos retos futuros, sobre todo, teniendo en cuenta que el Reino Unido parece proclive a abandonar el CEDH lo que pondría en peligro el esquema normativo determinado por la Human Rights Act 1998, de 9 de noviembre de 1998.

53. Así las cosas, las discrepancias entre órdenes en materia de privacidad son evidentes pues, siguiendo con los ejemplos mencionados, mientras que el legislador español tradicionalmente ha constreñido su protección a la esfera de la estricta intimidad, en el derecho inglés históricamente ni siquiera ha existido una noción equivalente. Por eso, la construcción de un orden público europeo en la cuestión ha devenido un factor clave en la tutela de la privacidad tal y como la coyuntura digital actual lo requiere, acabando con la disparidad normativa y de conformidad con la función adaptativa del Derecho a la realidad social.

\section{Conclusiones}

54. El siglo XXI se caracteriza por una omnipresencia de las nuevas tecnologías en todos los aspectos de la vida individual y colectiva, constituyendo un enorme cauce de desarrollo de la condición humana en todas sus esferas y provocando, en un periodo de tiempo relativamente corto, un cambio profundo en diversas facetas de la vida humana, desde el modo de comunicarse hasta el sistema de consumo, incluso en los propios patrones de comportamiento.

final de la sentencia: "This case nonetheless highlights, yet again, the failure of both the common law of England and statute to protect in an effective way the personal privacy of individual citizens". The Supreme Court of Judicature Court of Appeal (civil división) 16 marzo 1991, Kaye v. Robertson, [1991] FSR 62.

${ }^{62}$ El concepto rule of law es de una complejidad enorme, pues es un concepto "vago en lo que respecta a su contenido y promiscuo" en lo relativo a las funciones a desarrollar en un sistema constitucional que tiene la peculiaridad de no tener una norma constitucional. J. RAz, "The rule of law and its virtue" en The authority of law. Essays on law and morality, Oxford Clarendon Press, Oxford, 1979, p. 211.

${ }^{63}$ La STJCE 21 diciembre 2016, Tele2 Sverige AB \& Others v. Tom Watson, Peter Brice, Geoffrey Lewis, as. 203/15 y 698/15, ECLI:EU:C:2016:970; declaró que la Data Retention and Investigatory Powers Act 2014 (DRIPA), carecía de las salvaguardas mínimas y, en consecuencia, resultaba incompatible con la UE . Esta norma es la antecesora de la actual Investigatory Powers Act 2016 que la derogó y que ha devenido también muy polémica en tanto que aumenta considerablemente las prerrogativas de las autoridades británicas frente a la legislación anterior, cuyas extralimitaciones fueron las que llevaron al TJUE a declararla contraria a las leyes de la Unión. 
55. Este conjunto de factores, inherentes al desarrollo de la sociedad y aparejados a un gran número de ventajas y efectos positivos, también ha repercutido directamente en los derechos y las libertades, cuyo alcance y ejercicio se ha visto perturbado debido a la gran potencialidad lesiva de las tecnologías del Big data. La proliferación de datos personales que ocasionan éstas así como la memoria virtual y permanente que supone Internet, generan un almacenamiento, procesamiento y transferencia de información personal continuo que, en ocasiones, produce vulneraciones al derecho a la privacidad de los sujetos.

56. Parece evidente que la sociedad avanzada requiere repensar los términos y los medios de protección de las esfera privada de sus ciudadanos, como consecuencia lógica del desarrollo garantista de la intimidad personal frente a los desafíos que la nueva coyuntura ofrece para los bienes jurídicos. Las nuevas facetas de la vida privada requieren nuevos medios de tutela jurídica que deben ampliar su rango de protección en tanto que la esfera privada ha sido exponencialmente puesta en riesgo. En este sentido, las intromisiones en la privacidad de las personas, cada vez más frecuentes gracias a la intermediación de fenómenos relacionados como el avance de las nuevas tecnologías, la expansión del Big data o la democratización de Internet, no pueden quedar impunes por no cumplirse los requisitos que, tradicionalmente, se han venido exigiendo para la definición y la protección de la vida privada y familiar.

57. Así, en el contexto de la protección de datos, hablamos de privacidad para referirnos a la esfera de libertad que todo ser humano tiene respecto de sus datos de carácter personal, información que, si bien no en todas las ocasiones puede lesionar su intimidad, afecta a otra esfera menos restringida pero igualmente protegida por el Derecho. En consecuencia, debe abandonarse la concepción tradicional de la vida privada como un status negativo pues la protección de la privacidad, sin duda es un derecho activo de control, de autodeterminación, que permite a cada individuo controlar el ámbito de privacidad deseado, concediéndole asimismo herramientas efectivas para reaccionar frente a cualquier vulneración ${ }^{64}$.

58. Para la protección de la vida privada de los individuos en su conjunto, capaz de respetar la integridad de sus derechos y libertades, deviene necesario llevar a cabo una refundamentación de la privacidad que permita representar una esfera personal del sujeto libre de injerencias de terceros, mucho más amplia que el tradicional concepto de intimidad y como presupuesto indispensable para el ejercicio de la libertad individual, en tanto que es una garantía esencial para la protección de la dignidad y el libre desarrollo de la personalidad, de plena adecuación con el paradigma actual.

59. Se pretende así, reconocer la pluralidad de manifestaciones que tiene la esfera privada, concediendo a todas ellas protección jurídica, cuyo contenido, no obstante, variará de mayor a menor, en función de la cercanía al núcleo más íntimo de la personalidad. Asimismo, esta concepción de la privacidad, permite su protección más allá de los patrones existentes en cada momento determinado en tanto que la mutabilidad que le caracteriza obliga a ponerla en relación con el contexto histórico-social, el entorno cultural, el bien común y el status de la autonomía individual, en tanto que se trata de un concepto subjetivo también susceptible de influencias externas ${ }^{65}$.

60. Esto es lo que se ha tratado de hacer desde las diversas instancias europeas, mediante la promulgación de una legislación específica que sienta las bases de una estrategia comunitaria global así como adaptando los instrumentos jurídicos a las circunstancias concomitantes, desde de la jurispruden-

${ }^{64}$ WESTIN fue un pionero al examinar la privacidad desde un punto de vista positivo, identificando la privacidad con la facultad de control sobre nuestras propias informaciones. En este mismo sentido se posiciona el Reglamento europeo de protección de datos cuando hace mención al habeas data y configura la privacidad como una facultad de autodeterminación. A. F. WeSTIN, Privacy and freedom, Athenaeum, New York, 1967.

${ }^{65}$ La privacidad no es un valor absoluto por lo que la diversidad cultural y las infinitas vertientes de moralidad existentes convierten en una tarea extremadamente difícil estudiar la privacidad desde una perspectiva universal. Partiendo de la base de que la colectividad hace las normas y que el Derecho, al menos en las sociedades democráticas, es un conjunto de pautas de comportamiento comúnmente aceptadas, podemos concluir que éstas varían en función del contexto cultural. 
cia del Tribunal Europeo de Derechos Humanos o del Tribunal de Justicia de la Unión Europea. Gracias a la conformación de un orden público europeo en materia de privacidad se reconoce la pluralidad de manifestaciones que tiene la esfera privada, concediendo a todas ellas protección jurídica, partiendo de las circunstancias sociales, culturales e históricas que aconsejan ampliar el concepto y la garantía de lo privado desde una concepción unitaria y global ${ }^{66}$.

61. Las nuevas tecnologías e Internet no han creado nuevos bienes jurídicos protegidos, ni sustanciales cambios en los principios y valores del ordenamiento jurídico, pero indiscutiblemente han producido un aumento considerable de las vulneraciones de la esfera privada de los sujetos, llegando a ocasionar nuevas formas de lesión. Ello ha provocado un cambio de estrategia jurídica, con la intención de adaptarse a las nuevas circunstancias del medio, caracterizado por la participación de Internet en la vida privada y el almacenamiento y tráfico de datos personales inherente a las tecnologías del Big data, para tratar de dotar de garantía jurídica a los sujetos.

62. La reacción por parte del Derecho al escenario descrito, en su función de desarrollar mecanismos jurídicos adecuados para atender nuevas realidades, viene presidido por la creación de una estrategia europea común en materia de protección de datos que, entre otras cosas, pasa necesariamente por reconocer un ámbito de garantía de la vida privada más allá de la tradicional intimidad, concediendo protección jurídica a ciertos ámbitos personales de los individuos que, sin penetrar necesariamente en su estricta intimidad, calan en su esfera más privada, ocasionando igualmente molestias y perjuicios.

63. La conformación de un nuevo orden público europeo en materia de privacidad, ha venido ocasionando conflictos por las divergencias existentes en el propio concepto y significación de lo privado con los Estados miembros cuyos órdenes públicos internos e internacionales colisionan en esta cuestión. Así, por ejemplo, en el España este conflicto se vislumbró con la publicación del Reglamento (UE) no 2016/679 del Parlamento y del Consejo, de 27 de abril de 2016, relativo a la protección de las personas físicas en lo que respecta al tratamiento de datos personales y a la libre circulación de estos datos y por el que se deroga la Directiva 95/46/CE, entre otras muchas cuestiones, porque suscitaba dudas sustanciales en cuanto a la articulación de sus postulados con los tradicionales derechos ARCO de la doctrina española. También ha quedado reflejada la disparidad de criterios en torno a la conceptualización de la identidad de toda persona, por ejemplo, en cuanto al significado del nombre y los apellidos en este sentido.

64. En este caso, la jurisprudencia del Tribunal de Justicia de la Unión Europea ha resultado esencial para la protección de la privacidad, en conjunción con la protección de los datos personales, en nuestro ordenamiento, ocasionando una apertura del ámbito de tutela frente al reducto de garantía de la intimidad personal tradicionalmente concedido en la legislación doméstica. Como ejemplo paradigmático, la STJCE 13 mayo 2014, Google Spain, S.L., Google Inc. y Agencia Española de Protección de Datos, Mario Costeja González, as. 131/12, ECLI:EU:C:2014:317, que consitituye el leading case en materia de derecho al olvido, estableciendo lo que más tarde consagró el GDPR, entre otros, el reconocimiento del principio de extraterritorialidad, extendiendo la legislación y la estrategia comunitaria en materia de protección de datos más allá de los actores europeos.

65. El caso del Reino Unido es el ejemplo por antonomasia, primeramente porque su tradición jurídica del common law difiere notablemente del sistema continental en cuestiones tan básicas como la

\footnotetext{
${ }^{66}$ En este sentido, señala RALLO LOMBARTE que la constitucionalización española del fenómeno informático en sede de garantía de derechos fundamentales, debe analizarse desde una perspectiva global y comparada, pues los desarrollos legislativos más importantes de nuestro ordenamiento jurídico en dicha materia no constituyen tanto iniciativa propia nacional como el inevitable resultado de la obligación de cumplir con los compromisos internacionales adquiridos por España en el orden internacional y europeo. A. Rallo Lombarte, "De la libertad informática a la constitucionalización de nuevos derechos digitales (1978-2018)", Revista de Derecho Político, n 100, 2017, p. 643.
} 
concepción de la libertad individual o la vida privada y, mientras formaba parte de la Unión Europea, tuvo que aunar su sistema legal, íntimamente ligado al precedente judicial, con el positivismo jurídico propio de la integración europea, adoptando el principio de soberanía nacional mediante el cual se legitima al Parlamento para legislar en cualquier ámbito del Derecho. De hecho, hoy en día, la legislación británica no ofrece una definición concreta de lo que es o no privado ni tampoco reconoce expresamente el derecho a la privacidad, pese a que muchas de las facetas de esta noción han sido protegidas históricamente por normativa específica y por el propio common law.

66. La publicación de la Human Rights Act 1998, de 9 de noviembre de 1998, ha marcado un antes y un después para la protección de la privacidad en Reino Unido en tanto que, a partir de su entrada en vigor, las disposiciones del Convenio Europeo de Derechos Humanos de 1950 devienen directamente aplicables en el Derecho anglosajón el cual, además, queda directamente vinculado por la jurisprudencia del Tribunal Europeo de Derechos Humanos así como por la fluctuación de sus interpretaciones acerca de los conceptos jurídicos incluidos bajo el paraguas del Convenio. Ello ha supuesto una revolución jurídica para la protección del right to privacy, en relación con múltiples supuestos que, en el Derecho anglosajón, no habían tenido un reconocimiento previo o no se les había otorgado la tutela jurídica que se deriva del estatus de derecho fundamental.

67. Sin embargo, a tenor de lo expuesto a lo largo de este trabajo, parece claro que la estrategia comunitaria en materia de protección de datos personales deviene más garantista y concede una mayor protección para la protección de la privacidad de la ciudadanía, además de que parece más efectiva, teniendo en cuenta el medio en el que se producen las vulneraciones -Internet-, cuyo alcance es global, causando esterilidad en conceptos como "Estado" o "jurisdicción". La construcción de un orden público europeo en la cuestión ha devenido un factor clave en la tutela de la privacidad, en las condiciones que la realidad digital imperante exige, proporcionando tutela jurídica a numerosas situaciones que, de lo contrario, harían impunes a determinadas conductas lesivas o perjudiciales. Con ello, además, se pone fin a la disparidad normativa y se hace efectiva la función adaptativa del Derecho al contexto social. 